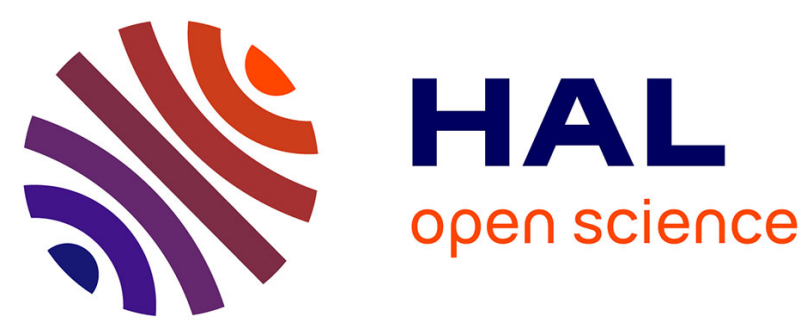

\title{
Quantification of the ferric/ferrous iron ratio in silicates by scanning transmission X-ray microscopy at the Fe L2,3 edges
}

Franck Bourdelle, Karim Benzerara, Olivier Beyssac, Julie Cosmidis, Daniel R. Neuville, Gordon E. Brown Jr., Erwan Paineau

\section{To cite this version:}

Franck Bourdelle, Karim Benzerara, Olivier Beyssac, Julie Cosmidis, Daniel R. Neuville, et al.. Quantification of the ferric/ferrous iron ratio in silicates by scanning transmission X-ray microscopy at the Fe L2,3 edges. Contributions to Mineralogy and Petrology, 2013, 166 (2), pp.423-434. 10.1007/s00410013-0883-4 . hal-02270197

\section{HAL Id: hal-02270197 https://hal.sorbonne-universite.fr/hal-02270197}

Submitted on 23 Aug 2019

HAL is a multi-disciplinary open access archive for the deposit and dissemination of scientific research documents, whether they are published or not. The documents may come from teaching and research institutions in France or abroad, or from public or private research centers.
L'archive ouverte pluridisciplinaire HAL, est destinée au dépôt et à la diffusion de documents scientifiques de niveau recherche, publiés ou non, émanant des établissements d'enseignement et de recherche français ou étrangers, des laboratoires publics ou privés. 
1 Quantification of the ferric/ferrous iron ratio in silicates by scanning transmission x-ray

2 microscopy at the $\mathrm{Fe} \mathrm{L}_{2,3}$ edges

3

4 Authors: Franck Bourdelle ${ }^{\mathrm{a}, \mathrm{b}}$, Karim Benzerara ${ }^{\mathrm{a}}$, Olivier Beyssac ${ }^{\mathrm{a}}$, Julie Cosmidis ${ }^{\mathrm{a}}$, Daniel

5 Neuville $^{\mathrm{c}}$, Gordon E. Brown Jr ${ }^{\mathrm{d}, \mathrm{e}}$, Erwan Paineau ${ }^{\mathrm{f}, \mathrm{g}}$

6

7 Mailing addresses of the relevant institutions:

9 a IMPMC, UPMC-CNRS, Case courrier 115, 4 Place Jussieu, 75252 Paris cedex 05, France

10 b GeoRessources, Université de Lorraine, UMR 7359 CNRS, 54506 Vandœuvre-lés-Nancy,

11 France

$12{ }^{\mathrm{c}}$ Géochimie et Cosmochimie, Institut de Physique du Globe de Paris, Université Paris

13 Diderot, Sorbonne Paris Cité, UMR 7154 CNRS, 1 rue Jussieu 75005 Paris, France

$14{ }^{\mathrm{d}}$ Surface \& Aqueous Geochemistry Group, Department of Geological and Environmental

15 Sciences, Stanford University, Stanford, CA, 94305-2115, USA

$16{ }^{\mathrm{e}}$ SLAC Natl Accelerator Lab, Stanford Synchrotron Radiation Lightsource, Menlo Pk, CA 1794025 USA

18 f Laboratoire de Physique des Solides, Université Paris-Sud, UMR 8502 CNRS, Bâtiment

19510,91405 Orsay cedex, France

$20{ }^{g}$ CEA Saclay, IRAMIS, Laboratoire Interdisciplinaire sur l'Organisation Nanométrique et

21 Supramoléculaire, 91191 Gif-sur-Yvette cedex, France

Corresponding authors:

1. Franck Bourdelle

Present mailing address: GeoRessources, Université de Lorraine, UMR 7359 CNRS, 54506

Vandœuvre-lés-Nancy, France

E-mail address: franck.bourdelle@gmail.com

28 Phone number: + $33(0) 383684728$

\section{Karim Benzerara}

31 Mailing address: IMPMC, UPMC-CNRS, Case courrier 115, 4 Place Jussieu, 75252 Paris

32 cedex 05, France

33 E-mail address: Karim.Benzerara@impmc.upmc.fr

34 Phone number: + 33 (0)1 44277542 


\section{Abstract}

Estimation of $\mathrm{Fe}^{3+} / \Sigma \mathrm{Fe}$ ratios in materials at the submicrometer scale has been a long-standing challenge in the Earth and environmental sciences because of the usefulness of this ratio in estimating redox conditions as well as for geothermometry. To date, few quantitative methods with submicrometric resolution have been developed for this purpose, and most of them have used electron energy-loss spectroscopy (EELS) carried out in the UHV environment of a transmission electron microscope (TEM). Scanning transmission $\mathrm{x}$-ray microscopy (STXM) is a relatively new technique complementary to TEM and is increasingly being used in the Earth sciences. Here, we detail an analytical procedure to quantify the $\mathrm{Fe}^{3+} / \Sigma \mathrm{Fe}$ ratio in silicates using Fe $\mathrm{L}_{2,3}$-edge $\mathrm{x}$-ray absorption near edge structure (XANES) spectra obtained by STXM, and we discuss its advantages and limitations. Two different methods for retrieving $\mathrm{Fe}^{3+} / \Sigma \mathrm{Fe}$ ratios from XANES spectra are calibrated using reference samples with known $\mathrm{Fe}^{3+}$ content by independent approaches. The first method uses the intensity ratio of the two major peaks at the $\mathrm{L}_{3}$-edge. This method allows mapping of $\mathrm{Fe}^{3+} / \Sigma \mathrm{Fe}$ ratios at a spatial scale better than $50 \mathrm{~nm}$ by the acquisition of 5 images only. The second method employs a 2-eV-wide integration window centred on the $\mathrm{L}_{2}$ maximum for $\mathrm{Fe}^{3+}$, which is compared to the total integral intensity of the $\mathrm{Fe}_{2}$-edge. These two approaches are applied to metapelites from the Glarus massif (Switzerland), containing micrometer-sized chlorite and illite grains and prepared as ultrathin foils by Focused Ion Beam milling. Nanometrer-scale mapping of iron redox in these samples is presented, and shows evidence of compositional zonation. The existence of such zonation has crucial implications for geothermometry and illustrates the importance of being able to measure $\mathrm{Fe}^{3+} / \Sigma \mathrm{Fe}$ ratios at the submicrometer scale in geological samples.

60

Keywords: ferric/ferrous iron, STXM, XANES spectroscopy, L2,3-edge, redox mapping, silicate.

Introduction

Determination of the redox state of iron and its spatial variations in sediments and rocks is of critical importance in both geosciences and environmental sciences, because of the need to understand redox state during their deposition or formation as well as subsequent 
changes in redox state due to weathering and other processes (e.g., de Andrade et al. 2006; Muñoz et al. 2006; Bernard et al. 2010; Benzerara et al. 2011; Bolfan-Casanova et al. 2012; Stagno et al. 2013). In addition, quantification of $\mathrm{Fe}^{3+} / \Sigma \mathrm{Fe}$ ratios can yield a better insight into the chemistry of complex geological materials (e.g., Muñoz et al. 2006), or a better estimation of $P-T$ conditions by geothermobarometers, when variations of the $\mathrm{Fe}^{3+}$ content within the crystals are taken into account (e.g., Schmid et al. 2003; de Andrade et al. 2006; Bourdelle et al. 2013a). Therefore, assessment of the $\mathrm{Fe}^{3+} / \Sigma \mathrm{Fe}$ ratio in minerals is an important and longstanding issue. Different techniques have been used extensively in the past for this purpose, including electron microprobe analysis (EMPA, e.g., Fialin et al. 2004), Mössbauer spectroscopy (e.g., Beaufort et al. 1992) X-ray photoelectron spectroscopy (XPS, e.g., Raeburn et al. 1997a, b), or x-ray absorption near edge structure (XANES) spectroscopy at the K edge (e.g., Waychunas et al. 1983; Bajt et al. 1994; Wilke et al. 2001, 2009; Berry et al. 2003, 2010). However, none of these methods provides spatial resolution at the few nanometers scale, which is particularly useful for studying chemical zonations patterns observed in low-temperature systems. Several studies (e.g., van Aken and Liebscher, 2002) have shown that electron energy-loss spectroscopy (EELS) carried out in a transmission electron microscope (TEM) is a powerful method for determining the redox state of iron at a submicrometer resolution. However it sometimes induces severe beam damage effects, such as electron beam-induced oxidation of iron (Lauterbach et al. 2000; Garvie et al. 2004), the effect of which can be corrected by measuring the signal as a function of time. Alternatively, XANES spectroscopy at the $\mathrm{Fe}_{2,3}$ edges carried out with a scanning transmission $\mathrm{x}$-ray microscope (STXM) has been increasingly used in the Earth and environmental sciences to infer qualitatively $\mathrm{Fe}^{3+} / \Sigma \mathrm{Fe}$ ratios in geological and environmental samples at a spatial resolution of 50-nm (e.g., Wasinger et al. 2003; Carlut et al. 2010; Lam et al. 2010; de Groot et al. 2010; Miot et al. 2011; Boulard et al. 2012). This technique has several advantages such as offering a high energy resolution (better than $0.1 \mathrm{eV}$ at existing synchrotron facilities) and the possibility of maintaining samples under anoxic conditions before and during the measurement (e.g., Miot et al. 2009). However, no calibration of the STXM-based Fe L $2,3^{-}$ edge XANES approach has yet been carried out, whereas calibration of the EELS approach was quantified by van Aken and Liebscher (2002). Fe $\mathrm{L}_{2,3}$-edges result from $2 p \rightarrow 3 d$ electronic transitions, as shown by Wasinger et al. (2003). These authors described in detail the physical basis of Fe L edges, and showed that information about iron valency can be retrieved from XANES spectra by a multiplet calculation approach (e.g., van der Laan and Kirkman, 1992; Cressey et al. 1993). This approach is difficult to apply when dealing with 
mineral phases for which we do not know the structure. Alternatively, fitting of XANES spectra with a linear combination of normalized reference spectra has been performed by Miot et al. (2009), but requires appropriate $\mathrm{Fe}^{2+}$ and $\mathrm{Fe}^{3+}$ end-member reference compounds with $\mathrm{Fe}$ in the same local coordination environment as in the sample of interest. Van Aken and Liebscher (2002) have shown the possibility of a third approach that they calibrated for EELS and which uses an empirical correlation between $\mathrm{Fe}^{3+} / \Sigma \mathrm{Fe}$ ratios and a parameter (i.e., modified integral white-line intensity ratio) which is directly retrieved from EELS spectra at the $\mathrm{Fe} \mathrm{L}_{2,3}$ edges, and is independent of the coordination environment of $\mathrm{Fe}$ to a the first-order approximation.

Here we propose an empirical approach similar to that of van Aken and Liebscher (2002) to calibrate the correlation between $\mathrm{Fe}^{3+} / \Sigma \mathrm{Fe}$ ratio and some parameters extracted from the STXM-derived XANES Fe $\mathrm{L}_{2,3}$-edge spectra of reference silicate glasses and phyllosilicates. Two empirical calibrations are proposed, both of which offer a compromise between speed and accuracy of the analytical measurement. An application of this approach to ultra-thin sections of natural chlorites and micas is presented to illustrate the methodology and to further assess the range of applicability of this calibration for STXM.

\section{Materials and Methods}

\section{Reference samples}

The samples used in this study were reference synthetic silicate glasses, natural phyllosilicates and fayalite, prepared as powders or ultra-thin sections cut by Focused Ion Beam (FIB) milling. The bulk chemical compositions of the five synthetic glasses were previously determined by Magnien et al. (2004). All samples are composed of similar proportions of $\mathrm{Si}, \mathrm{Mg}, \mathrm{Ca}, \mathrm{Na}$ and $\mathrm{Fe}$. The $\mathrm{SiO}_{2}$ and $\mathrm{FeO}$ contents are $\sim 52 \mathrm{wt} \%$ and $\sim 13 \mathrm{wt} \%$, respectively. Bulk $\mathrm{Fe}^{3+} / \Sigma \mathrm{Fe}$ ratios were determined by wet chemistry, Mössbauer spectroscopy and EMPA and range from 0.09 to 0.94 (Table 1; Magnien et al. 2004). For STXM-XANES analyses, we ground these samples in deaerated and deionized water, inside an anoxic glovebox $\left(\mathrm{p}\left(\mathrm{O}_{2}\right)<50 \mathrm{ppm}\right)$ to avoid oxidation during sample preparation.

The phyllosilicate samples have 2:1 and 2:1:1 structures and their bulk compositions were investigated previously by Joswig et al. (1986), Keeling et al. (2000), Shingaro et al. (2005), Rigault et al. (2010), and in the present study by EMP analyses. Total Fe contents vary significantly between samples and bulk $\mathrm{Fe}^{3+} / \Sigma \mathrm{Fe}$ ratios ranging between 0.03 and 1.0 
were measured by Mössbauer spectroscopy, EXAFS (extended x-ray absorption fine structure) and/or EELS (Table 1). In addition, a fayalite sample was used as a pure $\mathrm{Fe}^{2+}$ reference. For STXM-XANES analyses, some samples (smectite Nau-2, chlorites GAB 42, VNI 92, VNI 114, fayalite) were prepared by grinding in deaerated and deionized water in an anoxic glovebox $\left(\mathrm{p}\left(\mathrm{O}_{2}\right)<50 \mathrm{ppm}\right)$. Other samples (clintonite, chlorite 'prochlorite', chlorite Ch1, Ti-mica) where prepared by FIB milling.

Samples transparent to soft $\mathrm{x}$-rays are needed to measure XANES spectra in the transmission mode of STXM, therefore requiring the preparation of thin samples. FIB foils were cut with a FEI Model 200 TEM FIB system at University Aix-Marseille using the protocol detailed by Heaney et al. (2001). A $30 \mathrm{kV} \mathrm{Ga}^{+}$beam operating at $20 \mathrm{nA}$ excavated the sample to a depth of $5 \mu \mathrm{m}$. The sample foil was then further thinned to $\sim 80-100 \mathrm{~nm}$ at lower beam voltage $(5 \mathrm{kV})$ and current $(\sim 100 \mathrm{pA})$, in order to remove the layer damaged by high-energy ions (Bourdelle et al. 2012).

\section{Glarus field samples}

The Glarus Alps (Switzerland) belongs to the Helvetic zone of the northern margin of the Central Alps, and was affected by low-grade metamorphism. Details about the location and composition of the samples analyzed by STXM in the present study are provided in Lahfid et al. (2010). The selected rock samples are metapelites, more or less clayey or sandy marls, with various proportions of quartz, calcite, and clay minerals. Three samples (noted Glarus GL07 13, 16, and 20, as in Lahfid et al. 2010), containing chlorites and K-deficient micas, were milled by FIB. The compositions of the chlorites and micas were obtained on the FIB foils by analytical electron microscopy analyses described elsewhere (Bourdelle et al. 2012).

XANES spectroscopy

Part of the STXM analyses were performed at the Advanced Light Source (ALS) (Lawrence Berkeley National Laboratory) on branch line 11.0.2.2 following the procedures described in Miot et al. (2009). The ALS storage ring was operated at $1.9 \mathrm{GeV}$ and $500 \mathrm{~mA}$ current in a top-up mode. More details on the branch line 11.0.2.2 and beam characteristics are given by Bluhm et al. (2009). Stacks of images were obtained by scanning the sample in 
170

171

172

173

174

175

176

177

178

179

180

181

182

183

184

185

186

187

188

189

190

191

192

193

194

195

196

197

198

199

200

201

the $\mathrm{x}-\mathrm{y}$ directions of selected sample areas over the 690-730 eV energy range (Fe $\mathrm{L}_{2,3}$-edge) using an energy increment of $0.789 \mathrm{eV}$ between 690 and $705 \mathrm{eV}, 0.10 \mathrm{eV}$ in the $705-713 \mathrm{eV}$ energy range, $0.19 \mathrm{eV}$ in the $713-719 \mathrm{eV}$ energy range, $0.155 \mathrm{eV}$ in the $719-726 \mathrm{eV}$ energy range, and $0.475 \mathrm{eV}$ in the $726-730 \mathrm{eV}$ energy range. The dwell time per pixel and energy point was $1.3 \mathrm{~ms}$.

Some data (chlorite Ch1, chlorite 'prochlorite' and Ti-mica) were acquired on the Pollux beamline at the Swiss Light Source (SLS, Villigen, Switzerland). The SLS synchrotron storage ring was operated at $2.4 \mathrm{GeV}$ and $300 \mathrm{~mA}$ current in a top-up mode during data collection, and the characteristics of the beamline are detailed by Raabe et al. (2008). Stacks were obtained over the 690-730 eV energy range (Fe L 2,3 -edge) using an energy increment of $0.667 \mathrm{eV}$ between 690 and $700 \mathrm{eV}, 0.15 \mathrm{eV}$ in the 700-715 eV energy range, $0.40 \mathrm{eV}$ in the 715-727 eV energy ranges, and $0.89 \mathrm{eV}$ in the 727-730 eV energy range. The dwell time per pixel and energy point was $3.5 \mathrm{~ms}$.

At both the ALS and the SLS, focus was achieved systematically for each sample, and precision in the determination of the focus position was better than the focus depth. Image stacks were aligned and XANES spectra were derived from areas of interest using the aXis2000 software (Hitchcock, 2012). Potential beam damage caused by the incident photon beam was assessed by monitoring spectral changes at the Fe $\mathrm{L}_{2,3}$-edge with increasing dwell times up to a hundred milliseconds (10, 50, and $100 \mathrm{~ms})$.

\section{Spectra processing}

Energy calibration was performed using the gaseous neon $1 s \rightarrow 3 p$ electronic transition at $867.3 \mathrm{eV}$. As explained in Figure 1, the processing of spectra consisted of two steps. First, the contribution of lower energy absorption edges (i.e., background) was removed so that in the end, the pre-edge region is set to 0 optical density (noted OD) with a slope of zero. For that purpose, a "linear background" correction was applied to the spectrum. Second, the two edge steps resulting from transitions to unoccupied states in the continuum were subtracted using the following double arctan function (Chen et al. 1995; van Aken and Liebscher, 2002; Brotton et al. 2007):

$$
f(\Delta E)=\frac{h_{1}}{\pi}\left(\arctan \left[\frac{\pi}{w_{1}}\left(\Delta E-E_{1}\right)\right]+\frac{\pi}{2}\right)+\frac{h_{2}}{\pi}\left(\arctan \left[\frac{\pi}{w_{2}}\left(\Delta E-E_{2}\right)\right]+\frac{\pi}{2}\right)
$$


203 where $h_{1}$ and $h_{2}$ are the step heights of the two arctan functions, $w_{1}$ and $w_{2}$ are fixed peak widths, and $E_{1}$ and $E_{2}$ are the positions of the inflection points resulting in an energy near the edge onset. Here, $w_{1}$ and $w_{2}$ are fixed to $1 \mathrm{eV}$ (Fig. 1). Brotton et al. (2007) proposed setting the function slope $w$ at $5 \mathrm{eV}$, to account for the slow onset of the continuum. They argued that a value smaller than $5 \mathrm{eV}$ could induce spurious structures in the background-corrected spectrum. We observed that values of $w=1 \mathrm{eV}$ or $w=5 \mathrm{eV}$ provided similar results.

\section{Results and Discussion}

Evolution of $\mathrm{Fe} L_{2,3}-$ edge XANES spectra with changes in $\mathrm{Fe}^{3+} / \Sigma \mathrm{Fe}$

XANES spectra at the $\mathrm{Fe} \mathrm{L}_{2,3}$-edges of the reference phyllosilicates, fayalite and five Fe-bearing silicate glasses, corrected for continuum absorption, are shown in Figure 2, and the positions of major peaks are summarized in Table 1 . These spectra are qualitatively similar to those described in several previous studies and were obtained using different analytical techniques (e.g., Crocombette et al. 1995; Heijboer et al. 2003; van Aken and Liebscher, 2002). Four major Fe $\mathrm{L}_{2,3}$-edge XANES peaks are present in all samples. The two major peaks on the $\mathrm{L}_{3}$ edge are noted as " $\mathrm{L}_{3}-\mathrm{a}$ " and " $\mathrm{L}_{3}-\mathrm{b}$ ", and similarly, the major peaks on the $\mathrm{L}_{2}$ edge are noted as " $\mathrm{L}_{2}-\mathrm{a}$ " and " $\mathrm{L}_{2}-\mathrm{b}$ ". For all samples examined, the measured separations of the $\mathrm{Fe} \mathrm{L}_{3}$ and $\mathrm{L}_{2}$ maxima, due to spin-orbit splitting (van Aken and Liebscher, 2002), are 12.9 $\pm 0.4 \mathrm{eV}$ and $14.2 \pm 1.4 \mathrm{eV}$ for peaks a and $\mathrm{b}$, respectively in agreement with previous EELS and XANES studies (e.g., de Smit et al. 2008; de Groot et al. 2010). However, although most of the spectra show a single asymmetrical $\mathrm{L}_{3}$-a peak, some of them (i.e., VNI 92, VNI 114 and GAB 42, fayalite) display an " $\mathrm{L}_{3}-\mathrm{a}$ " split into two peaks. In addition, these specific spectra show additional peaks on the $\mathrm{L}_{3}$-a side at $\sim 706.3$ and $\sim 706.8 \mathrm{eV}$. According to Wasinger et al. (2003), the presence of these minor peaks may be due to a specific atomic environment and/or orbital co-valency of iron in these mineral phases. Similarly, several minor peaks can be observed at around $719.8 \mathrm{eV}$ on the $\mathrm{L}_{2}$-edge for several samples (VNI 92, VNI 114, GAB 42, PyrNa 17R, fayalite).

The relative intensities of the different major peaks vary depending on the $\mathrm{Fe}^{3+} / \Sigma \mathrm{Fe}$ ratio (Figure 2). With increasing $\mathrm{Fe}^{3+} / \Sigma \mathrm{Fe}$ ratios, the relative intensity of the $\mathrm{L}_{3}$-a peak 234 decreases compared to that of the $\mathrm{L}_{3}-\mathrm{b}$ peak; $\mathrm{L}_{3}-\mathrm{a}$ is more intense than $\mathrm{L}_{3}-\mathrm{b}$ in the XANES spectrum of the VNI 92 sample $\left(\mathrm{Fe}^{3+} / \Sigma \mathrm{Fe}=0.35\right)$, whereas the opposite is observed for PyrNa 
$5 \mathrm{R}\left(\mathrm{Fe}^{3+} / \Sigma \mathrm{Fe}=0.61\right)$. Likewise, the relative intensity of $\mathrm{L}_{2}$-a progressively decreases whereas that of $\mathrm{L}_{2}$-b increases as $\mathrm{Fe}^{3+} / \Sigma \mathrm{Fe}$ increases. The energy position of $\mathrm{L}_{2}$-b changes very little between the samples, whereas peaks $\mathrm{L}_{3}-\mathrm{a}$ and $\mathrm{L}_{2}-\mathrm{a}$ shift slightly towards higher energies when $\mathrm{Fe}^{3+} / \Sigma \mathrm{Fe}$ increases.

Quantification of $\mathrm{Fe}^{3+} / \Sigma \mathrm{Fe}$ from XANES Fe L2,3-edge intensity ratios

As documented in Figure 2, the main variations in the XANES spectra of reference samples with varying $\mathrm{Fe}^{3+} / \Sigma \mathrm{Fe}$ ratios involve the $\mathrm{L}_{3}-\mathrm{b} / \mathrm{L}_{3}-\mathrm{a}$ intensity ratio. More precisely, the $\mathrm{L}_{3}-\mathrm{b} / \mathrm{L}_{3}-\mathrm{a}$ intensity ratio is linearly correlated with $\mathrm{Fe}^{3+} / \Sigma \mathrm{Fe}$ ratio with only a little scatter $\left(\mathrm{R}^{2}\right.$ $=0.96$ ) for both the phyllosilicates and silicate glasses (Figure 3). The correlation is described by equation (2):

$$
\frac{F e^{3+}}{\sum F e}=\frac{R_{L_{3}}-0.1867}{0.01991} \quad \text { with } \quad R_{L_{3}}=\frac{I\left(L_{3}-b\right)}{I\left(L_{3}-a\right)}
$$

This approach requires only five XANES images to map $\mathrm{Fe}^{3+} / \Sigma \mathrm{Fe}$ (see Figure 4 and below): two images in the pre-edge (needed to apply the "linear background correction" at each pixel of the image), one at $708.7 \mathrm{eV}$ to quantify the $\mathrm{L}_{3}$-a peak, one at $710.25 \mathrm{eV}$ to quantify the $\mathrm{L}_{3}-$ $\mathrm{b}$ peak, and one at $718 \mathrm{eV}$, to remove the edge step of the arctan function. Finally, the ratio of the resulting 708.7 and $710.25 \mathrm{eV}$ images can be used to determine the $R_{L 3}$ parameter at each pixel of the image.

This calibration is useful but has some limitations. The $\mathrm{L}_{3}$ peaks, which are much more intense than the $\mathrm{L}_{2}$ peaks, are more susceptible to absorption saturation (see Hanhan et al. 2009, where saturation effects are described for Ca $2 p$ edge spectra). This phenomenon occurs when the sample is too thick and/or highly concentrated in Fe implying that few photons are transmitted. This may trigger a non-linear response of the detection and an artifactual modification of the relative peak heights. The use of a spectral parameter correlated with $\mathrm{Fe}^{3+} / \Sigma \mathrm{Fe}$ based on the less absorbing $\mathrm{L}_{2}$-edge may provide in this case an interesting way of circumventing absorption saturation issues encountered with the $\mathrm{L}_{3}$-edge.

Figure 2 shows that an increase of $\mathrm{Fe}^{3+} / \Sigma \mathrm{Fe}$ is associated with a decrease of the intensity of $\mathrm{L}_{2}$-a. Figure 5 shows the correlation between $\mathrm{Fe}^{3+} / \Sigma \mathrm{Fe}$ and $R_{L 2}$, a ratio that reflects the importance of $\mathrm{L}_{2}-\mathrm{b}$ relative to the total $\mathrm{L}_{2}$. Similar to the modified intensity defined by van Aken and Liebscher (2002), the $\mathrm{L}_{2}$-b contribution is computed as an integration window of 2 
$\mathrm{eV}$ width centred around the maximum $\mathrm{L}_{2}$-b intensity; the ratio $R_{L 2}$ is calculated from this modified $\mathrm{L}_{2}-\mathrm{b}$ intensity and the total integral intensity of $\mathrm{L}_{2}$-edge. The correlation is high $\left(\mathrm{R}^{2}\right.$ $=0.97$ ), and is described by equation (3):

$$
\frac{F e^{3+}}{\sum F e}=\frac{R_{L_{2}}-0.1476}{0.00297} \quad \text { with } \quad R_{L_{2}}=\frac{I\left(L_{2}-b\right)_{\bmod }}{A\left(L_{2}\right)_{\text {total }}}
$$

This approach requires the acquisition of a complete stack of images (i.e., as many images as energy points are required to obtain a complete spectrum with a given spectral resolution) between 715 and $730 \mathrm{eV}$, to cover the entire $\mathrm{L}_{2}$-edge, and to calculate the double arctan function (equation (1)). As a consequence, the acquisition time required for this method is longer than for the $\mathrm{L}_{3}-\mathrm{b} / \mathrm{L}_{3}-\mathrm{a}$ intensity ratio method (e.g. 30-40 min versus 5-10 min for an area of 150 by 150 pixels). However, this second method seems to be more accurate, especially because (1) the calibration data are less scattered (Fig. 5 versus Fig. 3) and (2) the intensity integration improves the signal-to-noise ratio. Several other methods of calibration have been tested, sometimes giving equation with a high correlation (with a $\mathrm{R}^{2}$ up to 0.95 ), but the two methods proposed here seem to be a good trade-off between $\mathrm{Fe}^{3+} / \Sigma \mathrm{Fe}$ estimation accuracy, acquisition time and ease of use.

\section{Assessment of saturation and beam damage effects}

When particles are sufficiently thin, the intensity of each spectral feature changes linearly with thickness. However, Hanhan et al. (2009) showed that in the case of samples that are too thick, one can observe distortions of the $\mathrm{Ca} 2 \mathrm{p}$ spectrum due to a saturation effects. These observations led the authors of that study to set a maximum peak intensity, which should not be exceeded to avoid saturation phenomena.

Similarly, we determined the maximum peak intensity below which the $\mathrm{Fe}_{23}$ spectra are undistorted and vary linearly. For this purpose, a powder of the smectite Nau-2 sample with grains of various sizes was analyzed by STXM. Figure 6 plots the difference between the intensities at $710.35\left(\mathrm{~L}_{3}-\mathrm{b}\right)$ and $723.54 \mathrm{eV}\left(\mathrm{L}_{2}-\mathrm{b}\right)$ (corrected from the pre-edge intensity) vs. the intensity at $710.35 \mathrm{eV}\left(\mathrm{L}_{3}-\mathrm{b}\right.$, i.e., the peak of maximum intensity for Nau-2, hence the most susceptible to saturation) for each pixel of the stack of images (i.e., a total of 6336 pixels). The difference between $\mathrm{L}_{3}-\mathrm{b}$ and $\mathrm{L}_{2}-\mathrm{b}$ intensities increases linearly when $\mathrm{L}_{3}-\mathrm{b}$ intensity is lower than $\sim 1.5 \mathrm{OD}$. Once the $\mathrm{L}_{3}-\mathrm{b}$ intensity exceeds $1.5 \mathrm{OD}$, the $\mathrm{L}_{3}-\mathrm{b}-\mathrm{L}_{2}-\mathrm{b}$ 
difference increases more slowly than $\mathrm{L}_{3}-\mathrm{b}$, underlining (i) the distortion of the spectra for the considered pixels, and (ii) the faster increase of $\mathrm{L}_{2}-\mathrm{b}$ intensity compared to that of $\mathrm{L}_{3}-\mathrm{b}$ with increasing sample thickness. All the data presented in this study were therefore collected from areas presenting a $\mathrm{L}_{3}$ peak intensity lower than 1.5 OD.

The spectrum may be also influenced by the crystal orientation relative to the direction of polarization of the X-ray beam, a process called linear dichroism. Therefore several XANES spectra were measured on the same part of a FIB foil after sequential rotation of the linear polarisation (see Benzerara et al., 2011 for details on the procedure). The variation of resulting $\mathrm{Fe}^{3+} / \Sigma \mathrm{Fe}$ estimates is negligible, showing that sample orientation does not affect the $\mathrm{Fe}^{3+}$ quantification.

Beam damage can also potentially alter assessment of the $\mathrm{Fe}^{3+} / \Sigma \mathrm{Fe}$ ratio. Here, beam damage was evaluated by monitoring spectral changes at the $\mathrm{Fe} \mathrm{L}_{2,3}$-edge with increasing dwell times from 10 up to 100 milliseconds. Figure 7 shows that $\mathrm{Fe}^{3+} / \Sigma \mathrm{Fe}$ ratios derived from XANES spectra are only slightly affected by increasing dwell time. In particular, no significant change was observed for typical dwell times used during routine analyses of the samples (i.e., 1.3 and $3.5 \mathrm{~ms}$ per energy- and image-point for ALS and SLS synchrotrons, respectively).

Application to a geological case: chlorites and micas from Glarus (Central Alps, Switzerland)

To go further, we have applied the methods proposed here on micrometer-sized chlorite and mica/illite-like grains sampled in the Glarus area of Switzerland and cut by FIBmilling. The temperatures of chlorite formation were calculated from analytical electron microscopy (AEM) chemical analyses, based on the thermometer by Bourdelle et al. (2013b), which does not require $\mathrm{Fe}^{3+} / \Sigma \mathrm{Fe}$ input, and the thermometer by Inoue et al. (2009), which needs a previous estimation of $\mathrm{Fe}^{3+}$ content. The $\mathrm{Fe}^{3+} / \Sigma \mathrm{Fe}$ ratios were estimated for each FIB foil by XANES from equations (2) and (3). The results are given in Figure 8 and Table 2.

From images converted to optical density units taken at $708.7 \mathrm{eV}$, we can easily distinguish Fe-rich and Fe-poor minerals: chlorites appear as light grey and represent the Ferich phase, whereas micas are dark, i.e., Fe-poor. XANES spectra, acquired along the micachlorite contacts show that the $\mathrm{Fe}^{3+} / \Sigma \mathrm{Fe}$ ratio is higher in illite than in chlorite: the $\mathrm{Fe}^{3+} / \Sigma \mathrm{Fe}$ ratios estimated by equation (3) range from $22.3 \%$ to $27.9 \%$ in chlorite, whereas these ratios vary between 30 and $65.5 \%$ in illite-like phase. Equation (2) provides consistent estimations, suggesting that both calibrations are reliable. This analysis shows that K-deficient micas can 
contain a high proportion of ferric iron (e.g. samples 13 and 20). Despite the relatively high $\mathrm{Fe}^{3+} / \Sigma \mathrm{Fe}$ ratio in some illite-like crystals, the total $\mathrm{Fe}^{3+}$ content remains higher in chlorite.

Figure 8 also shows the variations of $\mathrm{Fe}^{3+} / \Sigma \mathrm{Fe}$ ratios vs. the temperature of formation, which was estimated by chlorite thermometry (Table 2). In this respect, $\mathrm{Fe}^{3+} / \Sigma \mathrm{Fe}$ ratio increases slightly in chlorites with increasing temperature, whereas this ratio decreases in Kdeficient micas. It should be noted that, contrarily to the Bourdelle et al. (2013b) model, some geothermometers based on thermodynamic models for chlorite (e.g., Inoue et al. 2009), require prior determination of the $\mathrm{Fe}^{3+} / \Sigma \mathrm{Fe}$ ratio. When this value in not known, it is set to zero as the default in these types of models. Interestingly, the comparison of results provided by different thermometers in Table 2 shows that the Inoue and Bourdelle geothermometers yield very different temperature results (differences of up to $76^{\circ} \mathrm{C}$ ) when $\mathrm{Fe}^{3+} / \Sigma \mathrm{Fe}$ ratio is not known. In contrast, taking into account the $\mathrm{Fe}^{3+} / \Sigma \mathrm{Fe}$, the two thermometers provide more similar temperatures estimates (a maximum difference of less than $28^{\circ} \mathrm{C}$, i.e., within the uncertainty of the thermometers), showing the cross-check validity of the $\mathrm{Fe}^{3+} / \Sigma \mathrm{Fe}$ estimation. A variation of the $\mathrm{Fe}^{3+} / \Sigma \mathrm{Fe}$ ratio from 0 to $\sim 23 \%$ in chlorites implies a decrease in the temperatures calculated by the Inoue model of 20,40 , and $46^{\circ} \mathrm{C}$ depending on the sample.

Figure 9 displays an example of $\mathrm{Fe}^{3+} / \Sigma \mathrm{Fe}$ mapping at the nanometer-scale derived from images at 706, 708.7, 710.25, and $718 \mathrm{eV}$ using Eq. (2) (see Figure 4). The analysis was carried out on the Glarus GL07 20 FIB foil. The scanned area measures 3.3 x 3.5 micrometers with a pixel size of $88 \mathrm{~nm} \times 88 \mathrm{~nm}$. The analysis of the illite-chlorite contacts by AEM showed that they are approximately perpendicular to the FIB foil surface, i.e., there is only a little overlap between the two minerals at their contact. The spatial averaging effect of the $\mathrm{x}$ ray beam over the pixel size (i.e., $88 \mathrm{~nm}$ ) sets the limit of the minimum distance over which illite-chlorite contacts can be discriminated. Beyond this distance, the intracrystalline variation of the $\mathrm{Fe}^{3+} / \Sigma \mathrm{Fe}$ ratio in the illite-like phase can be interpreted as an authentic zonation, from $\sim 55 \%$ in crystal rims (conforming to the spectra presented in Figure 8 ) to $\sim 85 \%$ in several crystal core clusters. In the same way, the $\mathrm{Fe}^{3+} / \Sigma \mathrm{Fe}$ ratio distribution draws a subtle zonation in the chlorite, with a $\mathrm{Fe}^{3+} / \Sigma \mathrm{Fe}$ ratio ranging from 18 to $\sim 23 \%$ on the crystal rim, in accordance with the spectra shown in Figure 8. Such variations of the $\mathrm{Fe}^{3+} / \Sigma \mathrm{Fe}$ ratio within the crystals are equivalent to several degrees or tens of degrees in the temperature estimation, especially when this variation is associated with a variation in composition. One can expect that this zonation is a crucial issue in application of geothermometers (de Andrade et al. 2006; Bourdelle et al. 2013a), and the redox gap between illite and chlorite raises the issue of the crystallisation processes. 
In summary, the STXM-based XANES study of FIB foils from the Glarus, Switzerland samples enables (i) estimation of the $\mathrm{Fe}^{3+} / \Sigma \mathrm{Fe}$ ratio in each phase preserving the mineral texture, and (ii) establishment of iron redox mapping with high spatial resolution.

\section{Conclusion}

In this study, we have demonstrated the reliability of two methods that allow quantitative determination of $\mathrm{Fe}^{3+} / \Sigma \mathrm{Fe}$ ratios in silicate phases using STXM coupled with XANES spectroscopy at the $\mathrm{Fe} \mathrm{L}_{2,3}$-edges. These approaches are similar to those proposed by van Aken and Liebscher (2002) for EELS measurements but are here calibrated for STXM. The two calibrations are based on reference samples with variable but known $\mathrm{Fe}^{3+} / \Sigma \mathrm{Fe}$ ratios, which were prepared as powders or as FIB foils. We tested these calibrations on three FIB foils extracted from field samples of phyllosilicates (Glarus, Switzerland chlorite and illite samples from metapelites), demonstrating the potential of these methods for quantifying $\mathrm{Fe}^{3+} / \Sigma \mathrm{Fe}$ ratios at the submicrometer-scale. This approach will allow more quantitative mineralogical or geomicrobiological studies requiring estimation of the iron redox state at the nanoscale for terrestrial or extraterrestrial Fe-rich samples.

\section{Acknowledgements}

We are most grateful to the Lawrence Berkeley National Lab and especially to Tolek Tyliszczak for his scientific support, and the Paul Scherrer Institute, Swiss Light Source. We would like to thank the materials characterization department of IFP Energies nouvelles-Lyon and the laboratory of CP2M-Université Aix-Marseille, for technical advice. Thanks are also extended to Nicolas Menguy for his scientific help, and to Christian Chopin (ENS, Paris), Daniel Beaufort (IC2MP, Poitiers), Patricia Patrier (IC2MP, Poitiers) and the Muséum National d'Histoire Naturelle. This study was supported by a grant from the Simone and Cino del Duca Foundation.

\section{References}

Bajt S, Sutton SR, Delaney JS (1994) X-ray microprobe analysis of iron oxidation-states in silicates and oxides using X-ray-absorption near-edge structure (XANES). Geochim 
Beaufort D, Patrier P, Meunier A, Ottaviani MM (1992) Chemical variations in assemblages including epidote and/or chlorite in the fossil hydrothermal system of Saint Martin (Lesser Antilles). J Volcanol Geoth Res 51:95-114

Benzerara K, Miot J, Morin G, Ona-Nguema G, Skouri-Panet F, Ferard C (2011)

Significance, mechanisms and environmental implications of microbial biomineralization. $\mathrm{C}$ R Geosci 343 (2-3):160-167

Benzerara K, Menguy N, Obst M, Stolarski J, Mazur M, Tylisczak T, Brown, Jr., GE, Meibom A (2011) Study of the Crystallographic Architecture of Corals at the Nanoscale by Scanning Transmission X-ray Microscopy and Transmission Electron Microscopy.

Ultramicroscopy 111 (8): 1268-1275 Bernard S, Benzerara K, Beyssac O, Brown, Jr., GE (2010) Multiscale characterization of pyritized plant tissues in blueschist facies metamorphic rocks. Geochim Cosmochim Ac 74 (17):5054-5068

Berry AJ, O’Neill HS, Jayasuriya KD, Campbell SJ, Foran GJ (2003) XANES calibrations for the oxidation state of iron in a silicate glass 88 (7):967-977

Berry AJ, Yaxley GM, Woodland AB, Foran GJ (2010) A XANES calibration for determining the oxidation state of iron in mantle garnet. Chem Geol 278 (1-2):31-37

Bluhm, H., Andersson, K., Araki, T., Benzerara, K., Brown, J.G.E., Dynes, J.J., Ghosal, S., Gilles, M.K., Hansen, H.C., Hemminger, J.C., Hitchcock, A.P., Ketteler, G., Kilcoyne, A.L.D., Kneedler, E., Lawrence, J.R., Leppard, G.G., Majzlam, J., Mun, B.S., Myneni, S.C.B., Nilsson, A., Ogasawara, H., Ogletree, D.F., Pecher, K., Salmeron, M., Shuh, D.K., Tonner, B., Tyliszczak, T., Warwick, T. Yoon, T.H., 2006. Soft Xray microscopy and spectroscopy at the molecular environmental science beamline at the advanced light source. J Electron Spectrosc 150:86-104

Bolfan-Casanova N, Munoz M, McCammon C, Deloule E, Ferot A, Demouchy S, France L, Andrault D, Pascarelli S (2012) Ferric iron and water incorporation in wadsleyite under hydrous and oxidizing conditions: A XANES, Mossbauer, and SIMS study. Am Mineral 97 (8-9):1483-1493

Boulard E, Menguy N, Auzende AL, Benzerara K, Bureau H, Antonangeli D, Corgne A, Morard G, Siebert J, Perrillat JP, Guyot F, Fiquet G (2012) Experimental investigation of the stability of Fe-rich carbonates in the lower mantle. J Geophys Res-Solid Earth 117 Bourdelle F, Parra T, Beyssac O, Chopin C, Moreau F (2012) Ultrathin section preparation of phyllosilicates by Focused Ion Beam milling for quantitative analysis by TEM-EDX. Appl Clay Sci 59-60:121-130 
Bourdelle F, Parra T, Beyssac O, Chopin C, Vidal O (2013a) Clay minerals as geothermometer: A comparative study based on high-spatial-resolution analyses of illite and chlorite in Gulf Coast sandstones (Texas, USA). Am Mineral 98 (5-6):914-926

Bourdelle F, Parra T, Chopin C, Beyssac O (2013b) A new chlorite geothermometer for diagenetic to low-grade metamorphic conditions. Contrib Mineral Petr 165:723-735

Brotton SJ, Shapiro R, van der Laan G, Guo J, Glans PA, Ajello JM (2007) Valence state fossils in Proterozoic stromatolites by L-edge X-ray absorption spectroscopy. J Geophys Res-Biogeosci 112 (G3)

Carlut J, Benzerara K, Horen H, Menguy N, Janots D, Findling N, Addad A, Machouk I (2010) Microscopy study of biologically mediated alteration of natural mid-oceanic ridge basalts and magnetic implications. J Geophys Res-Biogeosci 115

Chen CT, Idzerda YU, Lin HJ, Smith NV, Meigs G, Chaban E, Ho GH, Pellegrin E, Sette F (1995) Experimental Confirmation of the X-Ray Magnetic Circular-Dichroism Sum-Rules for Iron and Cobalt. Phys Rev Lett 75 (1):152-155

Cressey G, Henderson CMB, Vanderlaan G (1993) Use of L-edge X-Ray-Absorption Spectroscopy to Characterize Multiple Valence States of 3d Transition-Metals - a New Probe for Mineralogical and Geochemical Research. Phys Chem Miner 20 (2):111-119 Crocombette JP, Pollak M, Jollet F, Thromat N, Gautiersoyer M (1995) X-Ray-Absorption Spectroscopy at the Fe L(2,3) Threshold in Iron-Oxides. Phys Rev B 52 (5):3143-3150 de Andrade V, Vidal O, Lewin E, O'Brien P, Agard P (2006) Quantification of electron microprobe compositional maps of rock thin sections: an optimized method and examples. J Metamorph Geol 24 (7):655-668

de Groot FMF, de Smit E, van Schooneveld MM, Aramburo LR, Weckhuysen BM (2010) Insitu Scanning Transmission X-Ray Microscopy of Catalytic Solids and Related Nanomaterials. ChemPhysChem 11 (5):951-962

de Smit E, Swart I, Creemer JF, Hoveling GH, Gilles MK, Tyliszczak T, Kooyman PJ, Zandbergen HW, Morin C, Weckhuysen BM, de Groot FMF (2008) Nanoscale chemical imaging of a working catalyst by scanning transmission X-ray microscopy. Nature 456 (7219):222-U239

Fialin M, Bézos A, Wagner C, Magnien V, Humler E (2004) Quantitative electron microprobe analysis of $\mathrm{Fe}^{3+} / \Sigma \mathrm{Fe}$ : Basic concepts and experimental protocol for glasses. Am Mineral 89 (4):654-662

Garvie LA, Zega TJ, Rez P, Buseck PR (2004) Nanometer-scale measurements of $\mathrm{Fe}^{3+} / \Sigma \mathrm{Fe}$ by electron energy-loss spectroscopy: A cautionary note. Am Mineral 89 (11-12):1610-1616 
Hanhan S, Smith AM, Obst M, Hitchcock AP (2009) Optimization of analysis of soft X-ray spectromicroscopy at the Ca 2p edge. J Electron Spectrosc 173 (1):44-49

Heaney PJ, Vicenzi EP, Giannuzzi LA, Livi KJT (2001) Focused ion beam milling: A method of site-specific sample extraction for microanalysis of Earth and planetary materials. Am Mineral 86 (9):1094-1099

Heijboer WM, Battiston AA, Knop-Gericke A, Havecker M, Mayer R, Bluhm H, Schlogl R, Weckhuysen BM, Koningsberger DC, de Groot FMF (2003) In-situ soft X-ray absorption of over-exchanged Fe/ZSM5. J Phys Chem B 107 (47):13069-13075

Hitchcock AP (2012) aXis 2000 Analysis of X-ray Images and Spectra. McMaster University, Hamilton, ON, Canada

Inoue A, Meunier A, Patrier-Mas P, Rigault C, Beaufort D, Vieillard P (2009) Application of chemical geothermometry to lowtemperature trioctahedral chlorites. Clay Clay Miner $57(3): 371-382$

Joswig W, Amthauer G, Takeuchi Y (1986) Neutron-diffraction and Mössbauer spectroscopic study of clintonite (xanthophyllite). Am Mineral 71:1194-1197

Keeling JL, Raven MD, Gates WP (2000) Geology and characterization of two hydrothermal nontronites from weathered metamorphic rocks at the Uley Graphite Mine, South Australia. Clay Clay Miner 48 (5):537-548

Lahfid A, Beyssac O, Deville E, Negro F, Chopin C, Goffe B (2010) Evolution of the Raman spectrum of carbonaceous material in low-grade metasediments of the Glarus Alps (Switzerland). Terra Nova 22 (5):354-360

Lam KP, Hitchcock AP, Obst M, Lawrence JR, Swerhone GDW, Leppard GG, Tyliszczak T, Karunakaran C, Wang J, Kaznatcheev K, Bazylinski DA, Lins U (2010) Characterizing magnetism of individual magnetosomes by X-ray magnetic circular dichroism in a scanning transmission X-ray microscope. Chem Geol 270 (1-4):110-116

Lauterbach S, McCammon CA, van Aken P, Langenhorst F, Seifert F (2000) Mossbauer and ELNES spectroscopy of $(\mathrm{Mg}, \mathrm{Fe})(\mathrm{Si}, \mathrm{Al}) \mathrm{O}_{3}$ perovskite: a highly oxidised component of the lower mantle. Contrib Mineral Petr 138 (1):17-26

Magnien V, Neuville DR, Cormier L, Mysen BO, Briois V, Belin S, Pinet O, Richet P (2004) Kinetics of iron oxidation in silicate melts: a preliminary XANES study. Chem Geol 213 (13):253-263

Miot J, Benzerara K, Morin G, Kappler A, Bernard S, Obst M, Ferard C, Skouri-Panet F, Guigner JM, Posth N, Galvez M, Brown, Jr., GE, Guyot F (2009) Iron biomineralization by anaerobic neutrophilic iron-oxidizing bacteria. Geochim Cosmochim Ac 73 (3):696-711 
Miot J, Maclellan K, Benzerara K, Boisset N (2011) Preservation of protein globules and peptidoglycan in the mineralized cell wall of nitrate-reducing, iron(II)-oxidizing bacteria: a cryo-electron microscopy study. Geobiology 9 (6):459-470

Munoz M, De Andrade V, Vidal O, Lewin E, Pascarelli S, Susini J (2006) Redox and speciation micromapping using dispersive X-ray absorption spectroscopy: Application to iron chlorite mineral of a metamorphic rock thin section. Geochem Geophys Geosyst 7

Raabe, J., Tzvetkov, G., Flechsig, U., Böge, M., Jaggi, A., Sarafimov, B., Vernooij, M.G.C., Huthwelker, T., Ade, H., Kilcoyne, D., Tyliszczak, T., Fink, R.H. Quitmann, C., 2008. PolLux: A new facility for soft X-ray spectromicroscopy at the Swiss Light Source. Rev Sci Instrum 79

Raeburn SP, Ilton ES, Veblen DR (1997a) Quantitative determination of the oxidation state of iron in biotite using X-ray photoelectron spectroscopy: I. Calibration. Geochim Cosmochim Ac 61 (21):4519-4530

Raeburn SP, Ilton ES, Veblen DR (1997b) Quantitative determination of the oxidation state of iron in biotite using X-ray photoelectron spectroscopy: II. In situ analyses. Geochim Cosmochim Ac 61 (21):4531-4537

Rigault C (2010) Cristallochimie de Fer dans les chlorites de basse température : implications pour la géothermométrie et la détermination des paléoconditions redox dans les gisements d'Uranium. University of Poitiers, Poitiers

Schingaro E, Scordari F, Mesto E, Brigatti MF, Pedrazzi G (2005) Cation-site partitioning in Ti-rich micas from Black Hill (Australia): A multi-technical approach. Clay Clay Miner 53 (2):179-189

Schmid R, Wilke M, Oberhänsli R, Janssens K, Falkenberg G, Franz L, Gaab A (2003) Micro-XANES determination of ferric iron and its application in thermobarometry. Lithos $70(3-4): 381-392$

Stagno V, Ojwang DO, McCammon CA, Frost DJ (2013) The oxidation state of the mantle and the extraction of carbon from Earth's interior. Nature 493: 84-88 van Aken PA, Liebscher B (2002) Quantification of ferrous/ferric ratios in minerals: new evaluation schemes of Fe L-23 electron energy-loss near-edge spectra. Phys Chem Miner 29 (3):188-200

van der Laan G, Kirkman IW (1992) The 2p Absorption-Spectra of 3d Transition-Metal Compounds in Tetrahedral and Octahedral Symmetry. J Phys-Condes Matter 4 (16):41894204 
538 Wasinger EC, de Groot FMF, Hedman B, Hodgson KO, Solomon EI (2003) L-edge X-ray absorption spectroscopy of non-heme iron sites: Experimental determination of differential orbital covalency. J Am Chem Soc 125 (42):12894-12906

541 Waychunas GA, Apted MJ, Brown, Jr., GE (1983) X-ray K-edge absorption spectra of Fe

542 minerals and model compounds: Near-edge structure. Phy Chem Min 10 (1):1-9

543 Wilke M, Farges F, Petit PE, Brown, Jr., GE, Martin F (2001) Oxidation state and

544 coordination of Fe in minerals: An FeK-XANES spectroscopic study. Am Mineral 86 (5-

545 6):714-730

546 Wilke M, Hahn O, Woodland AB, Rickers K (2009) The oxidation state of iron determined

547 by Fe K-edge XANES-application to iron gall ink in historical manuscripts. J Anal Atom

548 Spectrom $24(10): 1364-1372$

549

550 Tables

551

552 Table 1 Reference samples used for XANES $-\mathrm{Fe}^{3+} / \Sigma \mathrm{Fe}$ ratio quantification

553

\begin{tabular}{|c|c|c|c|c|c|c|c|c|}
\hline \multirow{2}{*}{ Type } & \multirow{2}{*}{ Sample } & \multirow{2}{*}{ Source } & \multirow{2}{*}{$\begin{array}{l}\mathrm{FeO} \\
\% \text { wt.* }\end{array}$} & \multirow{2}{*}{$\begin{array}{c}\mathrm{Fe}^{3+} / \Sigma \mathrm{Fe} \\
\text { Redox ratio }\end{array}$} & \multicolumn{4}{|c|}{$\begin{array}{l}\text { Position of maximum peak intensity } \\
\qquad(\mathrm{eV})\end{array}$} \\
\hline & & & & & $\mathrm{L}_{3}-\mathrm{a}$ & $\mathrm{L}_{3}-\mathrm{b}$ & $\mathrm{L}_{2}-\mathrm{a}$ & $\mathrm{L}_{2}-\mathrm{b}$ \\
\hline Silicate glass & PyrNa & Magnien et al. (2004) & 12.83 & $0.73 \pm 0.03$ & 708.57 & 710.04 & 721.68 & 723.54 \\
\hline Silicate glass & PyrNa17R & Magnien et al. (2004) & 12.75 & $0.09 \pm 0.01$ & 708.36 & 710.77 & 721.37 & 723.54 \\
\hline Silicate glass & PyrNa5R & Magnien et al. (2004) & 12.92 & $0.61 \pm 0.01$ & 708.57 & 710.04 & 721.68 & 723.54 \\
\hline Silicate glass & PyrNa750 & Magnien et al. (2004) & 12.68 & $0.94 \pm 0.03$ & 708.67 & 710.25 & 721.68 & 723.54 \\
\hline Silicate glass & PyrNa1200 & Magnien et al. (2004) & 13.52 & $0.89 \pm 0.05$ & 708.67 & 708.93 & 721.84 & 724.54 \\
\hline Nesosilicate & Fayalite & Neuville D. & 70.50 & $0.00 \pm 0.00^{\ddagger}$ & 708.09 & 710.71 & 720.75 & 723.54 \\
\hline Phyllosilicate & Smectite Nau-2 & Keeling et al. (2000) & 34.10 & $1.00 \pm 0.00^{\ddagger}$ & 708.57 & 710.35 & 721.84 & 723.54 \\
\hline Phyllosilicate & Clintonite & Joswig et al. (1986) & 3.01 & $0.69 \pm 0.03^{\ddagger}$ & 708.25 & 710.08 & 721.49 & 723.53 \\
\hline Phyllosilicate & Ti-mica & Shingaro et al. (2005) & 19.38 & $0.03 \pm 0.03^{\ddagger}$ & 708.04 & 710.04 & 721.00 & 723.54 \\
\hline Phyllosilicate & Chlorite 'Prochlorite' & $\mathrm{MNHN}^{\dagger}$ & 14.50 & $0.30 \pm 0.10^{\ddagger}$ & 708.26 & 710.21 & 721.51 & 723.51 \\
\hline Phyllosilicate & Chlorite Ch1 & This study & 40.10 & $0.17 \pm 0.05$ & 708.04 & 710.19 & 721.00 & 723.54 \\
\hline Phyllosilicate & Chlorite GAB 42 & Rigault (2010) & 28.50 & $0.14 \pm 0.03$ & 708.15 & 710.46 & 720.75 & 723.54 \\
\hline Phyllosilicate & Chlorite VNI 92 & Rigault (2010) & 20.73 & $0.35 \pm 0.03$ & 708.15 & 710.25 & 720.75 & 723.54 \\
\hline Phyllosilicate & Chlorite VNI 114 & Rigault (2010) & 20.82 & $0.20 \pm 0.03$ & 708.04 & 710.25 & 720.75 & 723.54 \\
\hline
\end{tabular}

$554 * \Sigma$ Oxides $\mathrm{wt} \%=100$ as basis and all iron reported as ferrous. ${ }^{\dagger}$ MNHN: Collection of Muséum National

555 d'Histoire Naturelle, France. ${ }^{\star}$ assumed error deviation. 
557 Table 2 AEM chemical representative analyses of Glarus chlorites and comparison of

558 thermometers results taking into account $\mathrm{Fe}^{3+} / \Sigma \mathrm{Fe}$ ratios (Eq. (3)); regarding the scatter of

559 data on Figure 3, we infer a precision of $\pm 5 \%$ on the $\mathrm{Fe}^{3+} / \Sigma \mathrm{Fe}$. Analyses were carried out on

560 crystal rims, along the illite-chlorite contact, according to Bourdelle et al. (2013a).

561 Temperature estimations were performed with Bourdelle et al. (2013b) and Inoue et al. (2009)

562 thermometers, with and without consideration of $\mathrm{Fe}^{3+}$, in accordance with the

563 recommendations made by each authors. Taking into account the $\mathrm{Fe}^{3+} / \Sigma \mathrm{Fe}$ ratios in the Inoue

564 model allows to obtain similar results to those calculated with the Bourdelle model (which is

565 a pure $\mathrm{Fe}^{2+}$ model), i.e., with a difference less than $30^{\circ} \mathrm{C}$ (equivalent to the uncertainty of each 566 model)

567

\begin{tabular}{lccc}
\hline Chlorite [\%wt] & GL07 13 & GL07 20 & GL07 16 \\
\hline $\mathrm{SiO}_{2}$ & 32.70 & 31.40 & 31.57 \\
$\mathrm{TiO}_{2}$ & 0.07 & 0.06 & 0.04 \\
$\mathrm{Al}_{2} \mathrm{O}_{3}$ & 26.41 & 25.56 & 26.02 \\
$\mathrm{FeO}$ & 26.63 & 28.53 & 25.13 \\
$\mathrm{MnO}$ & 0.00 & 0.00 & 0.00 \\
$\mathrm{MgO}$ & 13.75 & 13.97 & 16.70 \\
$\mathrm{CaO}$ & 0.06 & 0.10 & 0.29 \\
$\mathrm{Na} 2 \mathrm{O}$ & 0.00 & 0.04 & 0.00 \\
$\mathrm{~K}_{2} \mathrm{O}$ & 0.39 & 0.35 & 0.25 \\
$\mathrm{Fe}^{3+} / \Sigma \mathrm{Fe}[\%]$ & 22.30 & 23.80 & 27.90 \\
$\mathrm{~T}_{\mathrm{BOU}}\left[{ }^{\circ} \mathrm{C}\right]$ & 135 & 170 & 182 \\
$\mathrm{~T}_{\mathrm{INO}-\mathrm{Fe}+}\left[{ }^{\circ} \mathrm{C}\right]$ & $165(+30)$ & $236(+66)$ & $258(+76)$ \\
$\mathrm{T}_{\text {INO-Fe3+ }+}\left[{ }^{\circ} \mathrm{C}\right]$ & $145(+10)$ & $196(+26)$ & $210(+28)$ \\
\hline
\end{tabular}

$568 \mathrm{~T}_{\text {BOU }}$ : temperatures calculated with the $\mathrm{Fe}^{2+}$-pure model of Bourdelle et al. (2013b), considering $\mathrm{Fe}_{\mathrm{tot}}=\mathrm{Fe}^{2+}$.

$569 \mathrm{~T}_{\mathrm{INO}-\mathrm{Fe} 2+}$ : temperatures calculated with the Inoue et al. (2009) model, considering $\mathrm{Fe}_{\text {tot }}=\mathrm{Fe}^{2+}$. $\mathrm{T}_{\mathrm{INO}-\mathrm{Fe} 3+}$ :

570 temperatures calculated with the Inoue et al. (2009) model, using the estimated $\mathrm{Fe}^{3+} / \Sigma \mathrm{Fe}$.

\section{Figures}




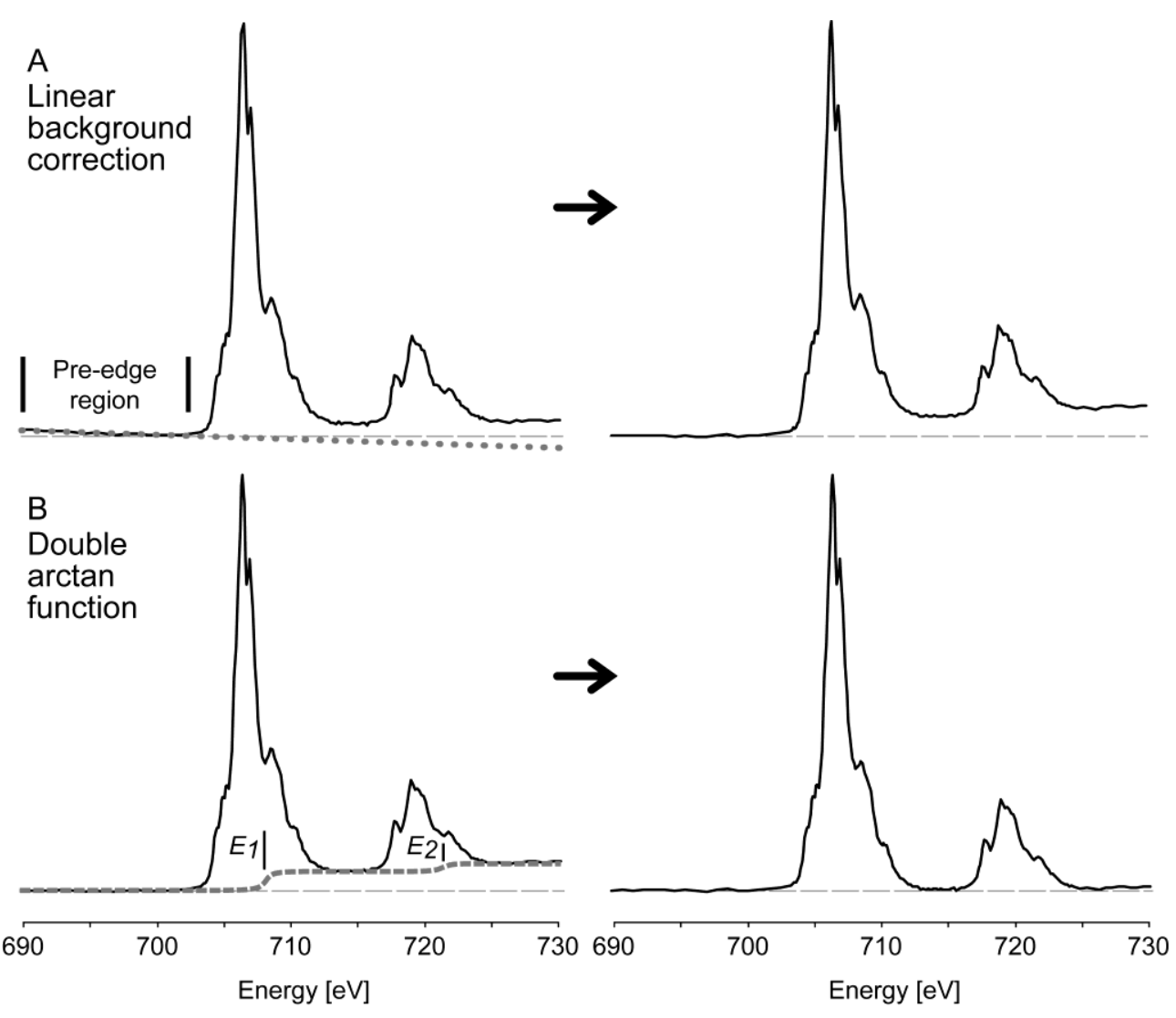

Fig. 1 Subtraction of background from XANES spectra at Fe L-edge, using linear and double

$576 \arctan$ functions $\left(w_{1}=w_{2}=1 \mathrm{eV}\right)$, for chlorite GAB 42 


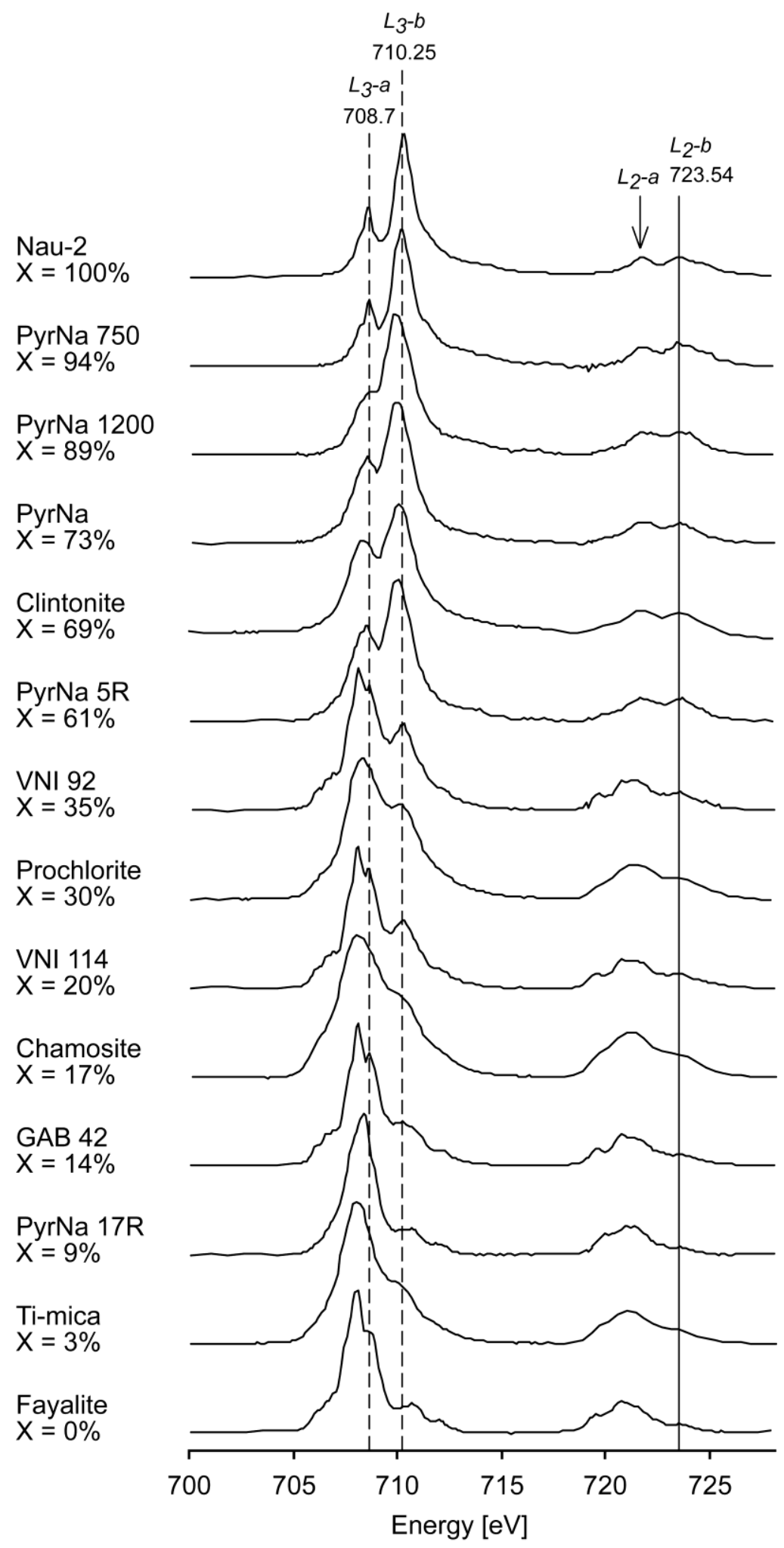

Fig. 2 Representative XANES spectra at the Fe $\mathrm{L}_{2,3}$-edges for the reference silicates. The

580 spectra have been normalised to the integral $\mathrm{Fe} \mathrm{L}_{3}$-edge intensity, and some of the spectra

581 have been shifted vertically for clarity (normalized intensity with arbitrary units). The dotted

582 lines represent the energies fixed to determine the $\mathrm{Fe}^{3+}$ concentration from the $\mathrm{Fe}_{2} \mathrm{~L}_{3}-\mathrm{peaks}$ ' 
583 intensity ratio. The solid line underlines the position of $\mathrm{L}_{2}-\mathrm{b}$ maximum intensity, which is 584 identical for all spectra. $\mathrm{X}=\mathrm{Fe}^{3+} / \Sigma \mathrm{Fe}$ ratios of Table 1

585

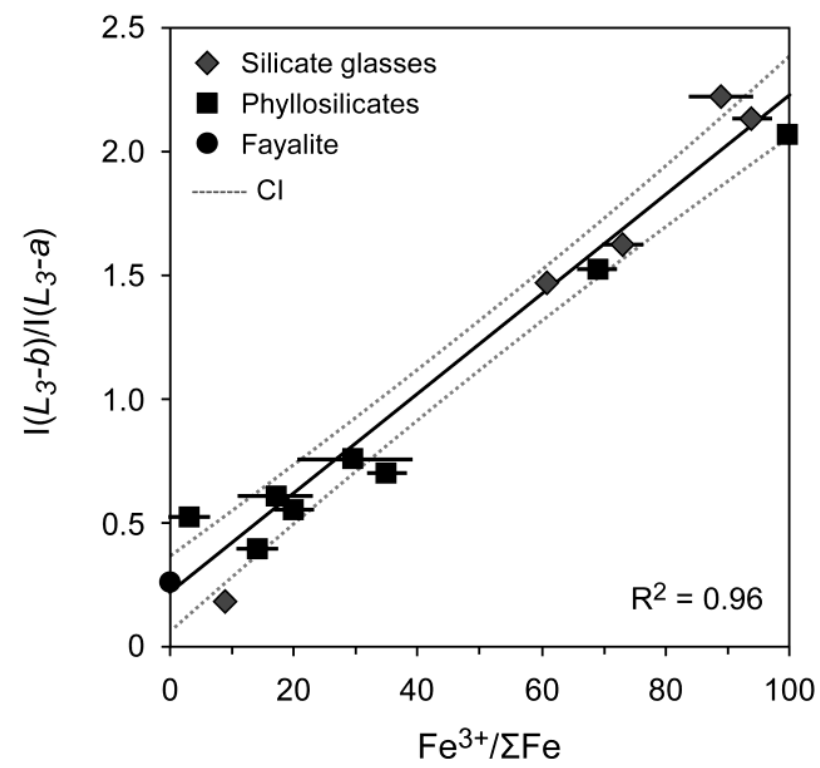

586

587 Fig. $3 L_{3}$-edge intensity ratio $I\left(L_{3}-b\right) / I\left(L_{3}-a\right)$ from XANES spectra versus ferric iron

588 concentration $\mathrm{Fe}^{3+} / \Sigma \mathrm{Fe}$ quantified by independent methods for the selected silicates. $\mathrm{CI}$ :

589 confidence interval (95\%)

590 


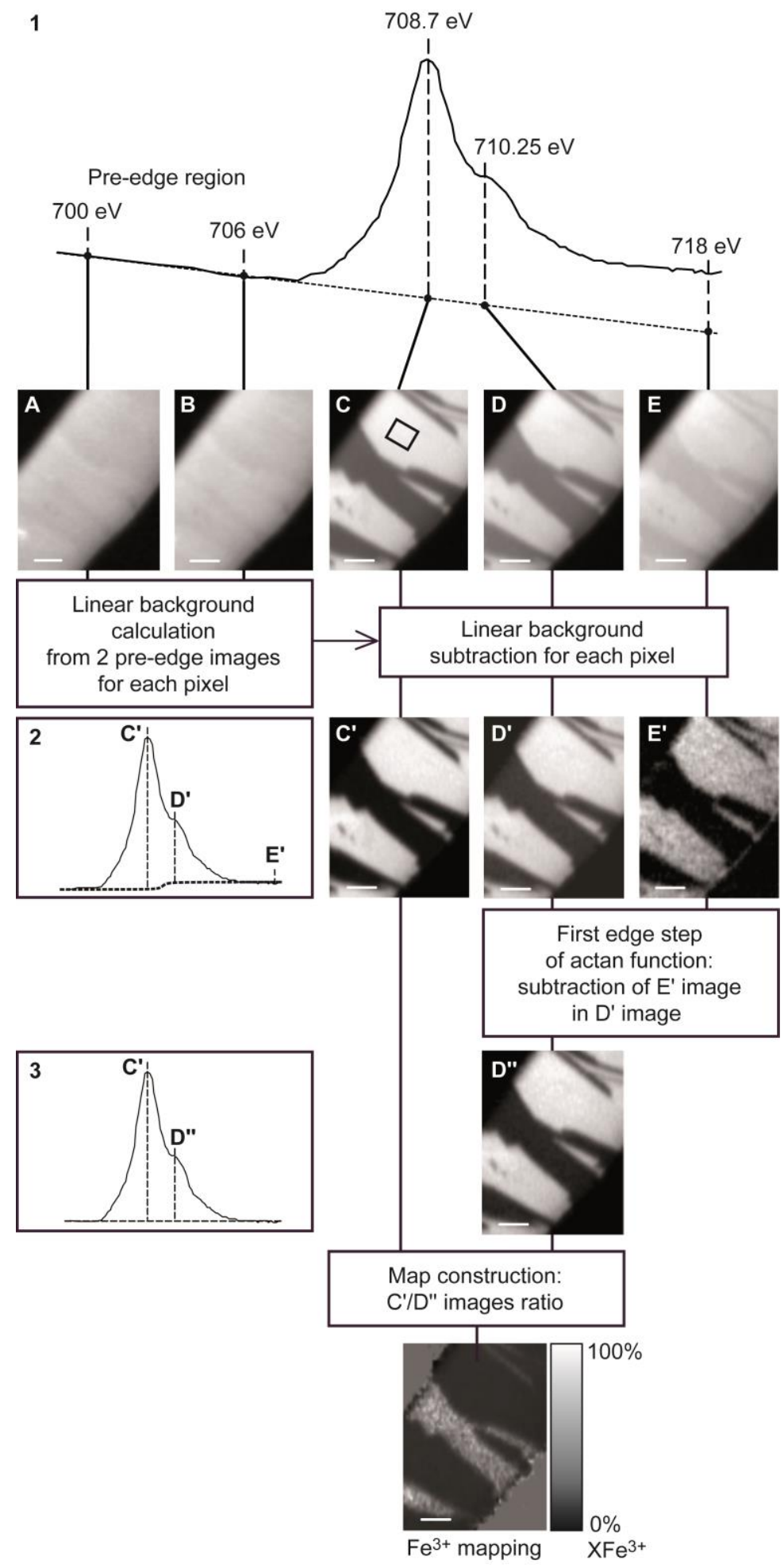

592 Fig. 4 Determination of the $\mathrm{Fe}^{3+} / \Sigma \mathrm{Fe}$ ratio from 5 selected energy images: two images in the 593 pre-edge (to apply the "linear background correction" at each pixel of the image), one at 708.7

$594 \mathrm{eV}$ to quantify the $\mathrm{L}_{3}-\mathrm{a}$ peak, one at $710.25 \mathrm{eV}$ to quantify the $\mathrm{L}_{3}-\mathrm{b}$ peak, and one at $718 \mathrm{eV}$, 595 to remove the edge step of the arctan function. Finally, the ratio of the resulting 708.7 and $596710.25 \mathrm{eV}$ images can be used to determine the $R_{L 3}$ parameter at each pixel of the image, and 597 obtain iron redox mapping. All images are OD images (70 x 90 pixels), where the illite and 
598 chlorite are the dark- and light- grey phases, respectively. As an illustration, spectrum \#1 was 599 retrieved from 110 images (i.e., 110 energy points) on a chlorite area (dark rectangle on image 600 C); spectrum \#2 was obtained after the linear function subtraction from spectrum \#1 and 601 spectrum \#3 after the actan function subtraction from spectrum \#2. Case of FIB foil of Glarus 602 GL07 20 sample.

603

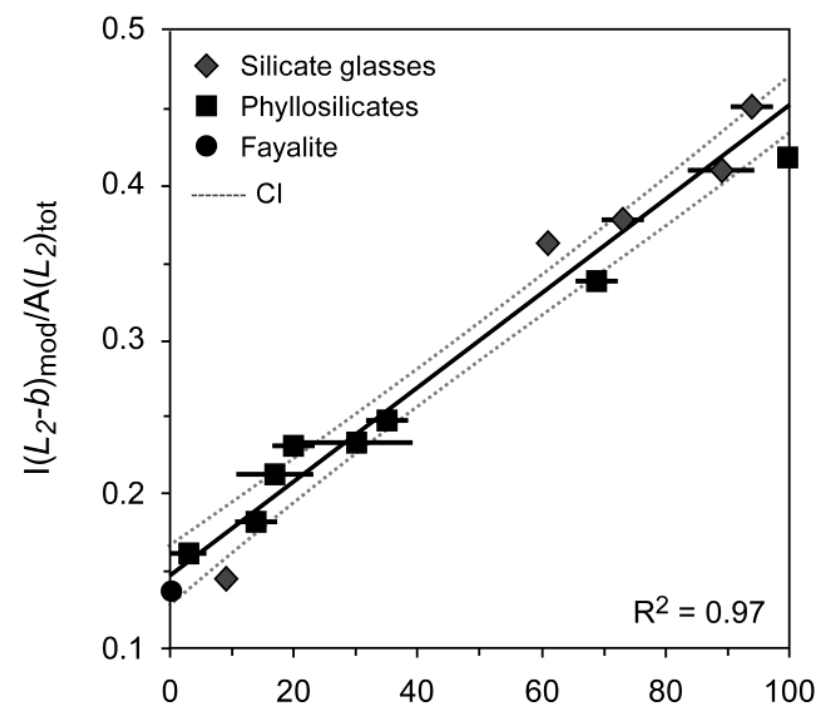

604 $\mathrm{Fe}^{3+} / \Sigma \mathrm{Fe}$

605 Fig. $5 \mathrm{~L}_{2}$-edge integral intensity ratio (i.e., integral intensity of maximum $\mathrm{L}_{2}-\mathrm{b} \pm 0.1 \mathrm{eV}$ over 606 total integral intensity (area) of $\mathrm{L}_{2}$-edge) from XANES spectra versus ferric iron 607 concentration $\mathrm{Fe}^{3+} / \Sigma \mathrm{Fe}$ quantified by independent methods for the reference silicates. CI: 608 confidence interval $(95 \%)$ 


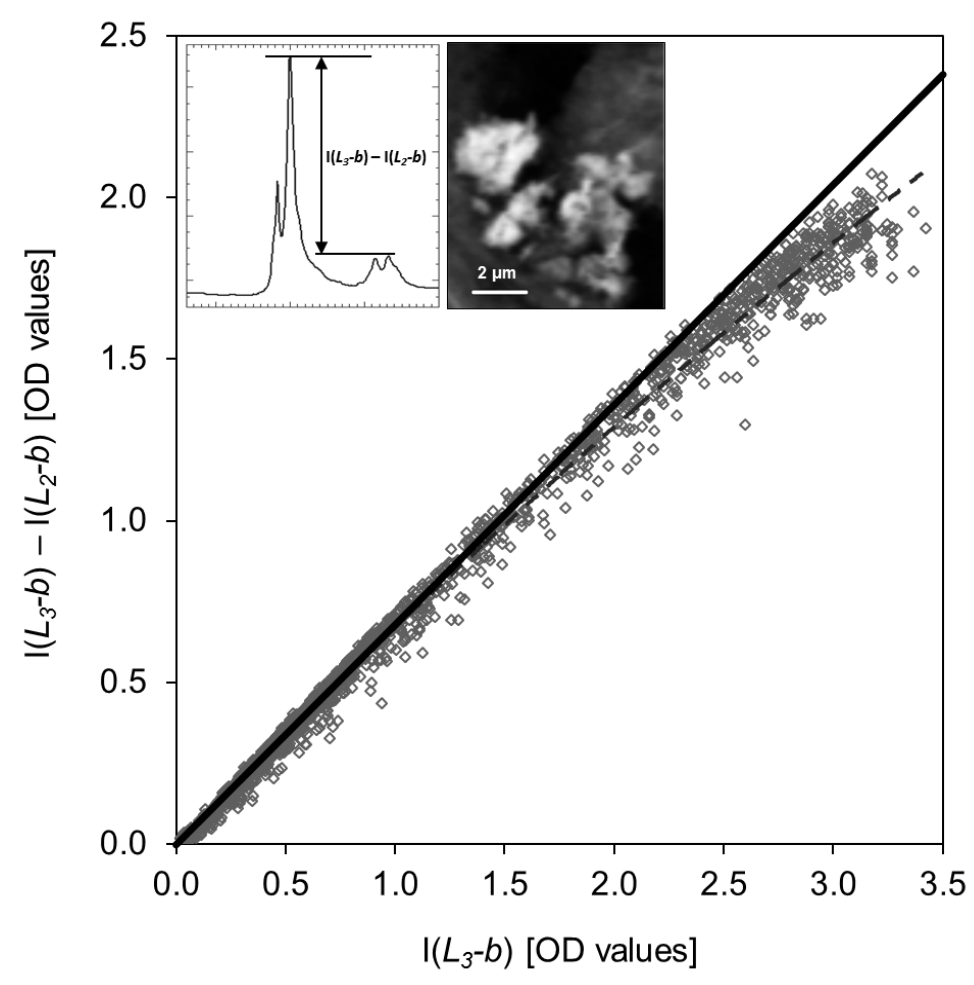

610

611 Fig. 6 Difference, pixel by pixel, of intensity detected between the 710.25 and the $723.54 \mathrm{eV}$ 612 images (in which a pre-edge image was not subtracted) versus the intensity of the $710.25 \mathrm{eV}$ 613 image of a Smectite Nau-2 STXM-map (Nau-2, 72 x 88 pixels $=6336$ points), i.e., the L $\mathrm{L}_{3}-\mathrm{b}-$ $614 \mathrm{~L}_{2}-\mathrm{b}$ intensity difference versus the $\mathrm{L}_{3}-\mathrm{b}$ intensity for each pixel. The dashed line was 615 calculated from a quadratic equation. Insets: representative spectra and optical density image 616 (710.25 eV) for Nau-2 sample

617 


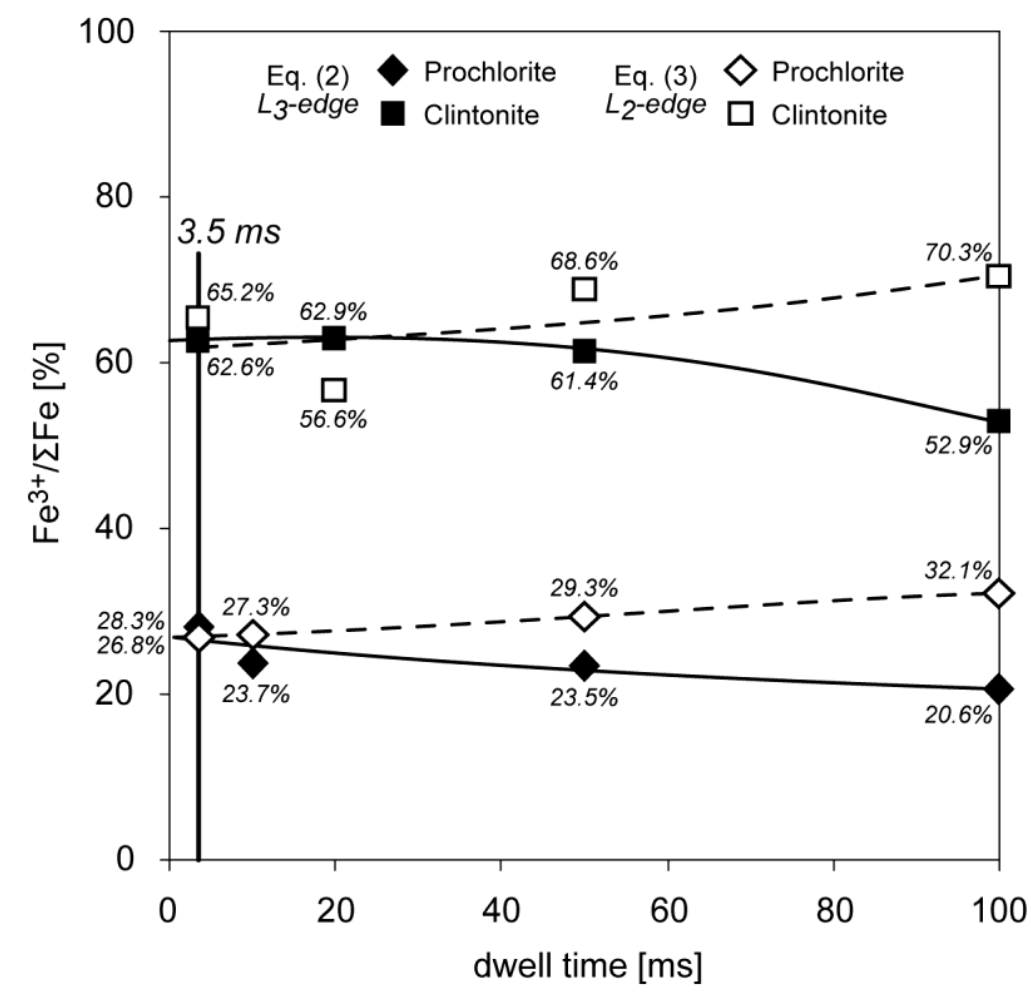

Fig. 7 Beam-induced radiation damage during STXM analyses of chlorite 'prochlorite'

$620\left(\mathrm{XFe}^{3+}=30 \%\right)$ and clintonite $\left(\mathrm{XFe}^{3+}=69 \%\right)$. Evolution of the $\mathrm{Fe}^{3+} / \Sigma \mathrm{Fe}$ ratios as a function of 621 dwell time, estimated by Eq. (2) and (3) from XANES spectra. Data were fit by a quadratic 622 function. The beam radiations (increasing dwell) involve (1) a decrease of $\mathrm{XFe}^{3+}$ calculated 623 from $\mathrm{L}_{3}$-edge (Eq. 2) and (2) an increase of $\mathrm{XFe}^{3+}$ calculated from $\mathrm{L}_{2}$-edge (Eq. 3). Spectra of 624 reference samples and Glarus samples (see text) were recorded with a dwell time of 1.3-

$6253.5 \mathrm{~ms}$ per point and energy: the beam radiation damage is thus negligible with our analytical 626 conditions for data collection 


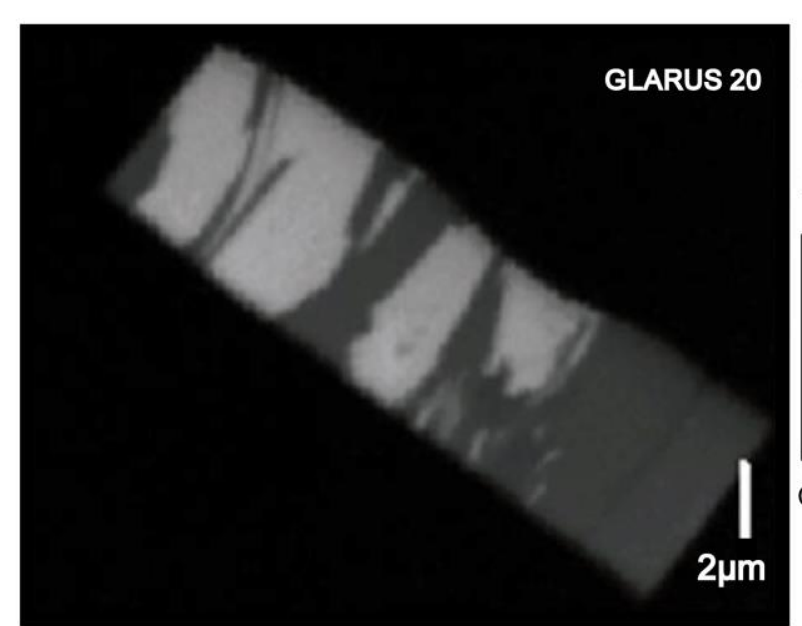

Optical density STXM-images of FIB sections (708.7 eV)

$\mathrm{X}$ axis: energy [ 5 by $5 \mathrm{eV}] \mathrm{Y}$ axis: arbitrary unit
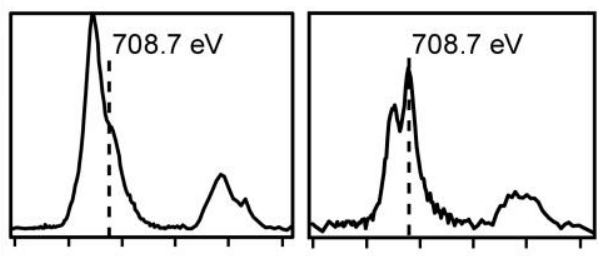

Chlorite (Fe-rich phase) Illite (Fe-poor phase)

$$
\begin{gathered}
\mathrm{Fe}^{3+} / \Sigma \mathrm{Fe} \\
23.1 \% \text { (Eq. 2) } \\
23.8 \% \text { (Eq. 3) }
\end{gathered}
$$

$$
\mathrm{Fe}^{3+} / \Sigma \mathrm{Fe}
$$

$$
57.4 \% \text { (Eq. 2) }
$$
$57.7 \%$ (Eq. 3)
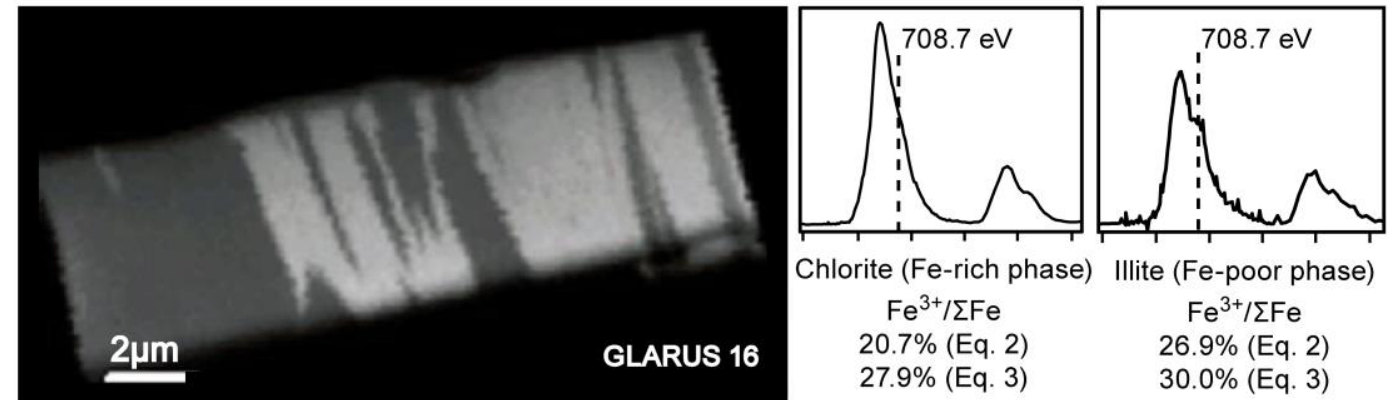

Chlorite (Fe-rich phase) Illite (Fe-poor phase)

$$
\mathrm{Fe}^{3+} / \Sigma \mathrm{Fe}
$$

$20.7 \%$ (Eq. 2)

$27.9 \%$ (Eq. 3)

$$
\mathrm{Fe}^{3+} / \Sigma \mathrm{Fe}
$$

$26.9 \%$ (Eq. 2)

$30.0 \%$ (Eq. 3)
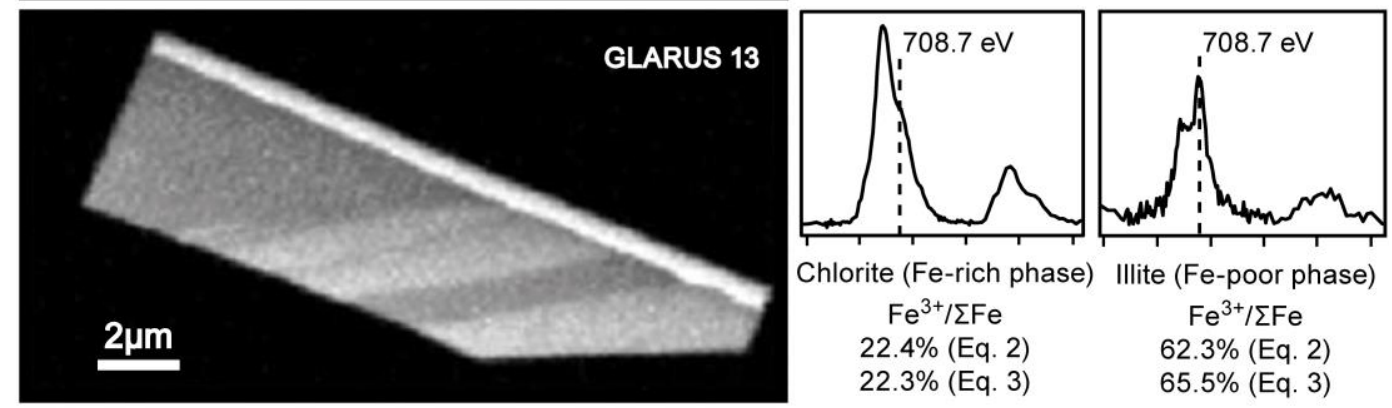

Chlorite (Fe-rich phase) Illite (Fe-poor phase)

$$
\begin{array}{cc}
\mathrm{Fe}^{3+} / \Sigma \mathrm{Fe} & \mathrm{Fe}^{3+} / \Sigma \mathrm{Fe} \\
22.4 \% \text { (Eq. 2) } & 62.3 \% \text { (Eq. 2) } \\
22.3 \% \text { (Eq. 3) } & 65.5 \% \text { (Eq. 3) }
\end{array}
$$

629 Fig. 8 Scanning transmission $\mathrm{x}$-ray microscopy (STXM) and XANES analysis and $\mathrm{Fe}^{3+} / \Sigma \mathrm{Fe}$

630 estimations for FIB foils of Glarus samples (chlorite and illite). [Left] Optical density images

631 of FIB foils at $708.7 \mathrm{eV}$. The illite and chlorite are the dark- and light- grey phases,

632 respectively. [Right] XANES spectra of areas of interest and calculated $\mathrm{Fe}^{3+}$ concentrations

633 associated (crystals rims)

634 


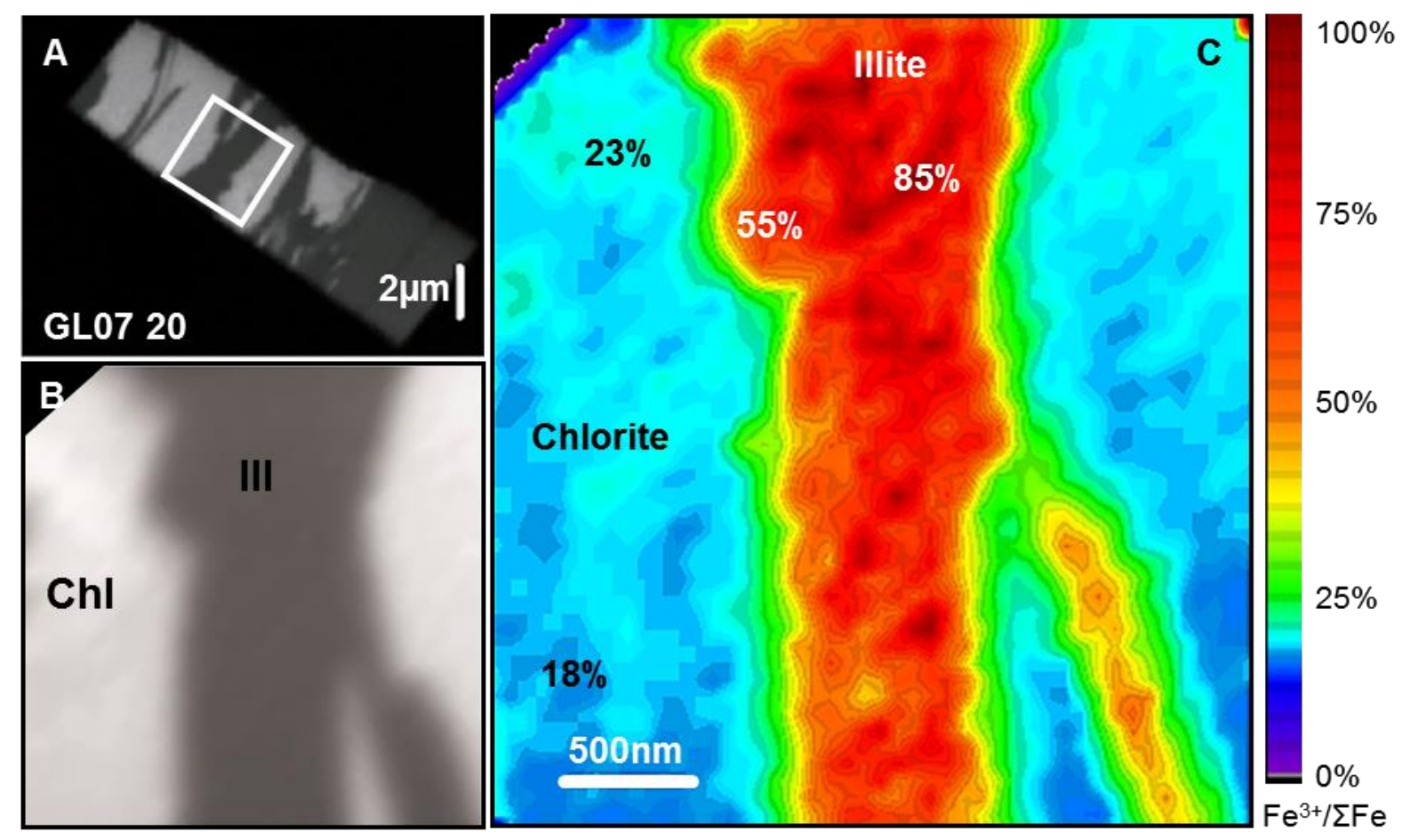

Fig. 9 Quantitative Fe redox nanomapping on FIB foil of Glarus GL07 20 sample. (a) Optical density image at $708.7 \mathrm{eV}$ of Glarus GL07 20 FIB section, where the illite and chlorite are the dark- and light- grey phases, respectively. (b) Optical density image at $708.7 \mathrm{eV}$ of the area of interest. (c) iron redox mapping, calculated from the 708.7 to $710.25 \mathrm{eV}$ images ratio coupled with Eq. (2). The illite-chlorite contacts were analysed by AEM to check that they are approximately perpendicular to the FIB foil surface, i.e., there is only a small overlap between

642 the two minerals at their contact. The spatial averaging effect of the x-ray beam over the pixel 643 size (i.e., $88 \mathrm{~nm}$ ) sets the limit of the minimum distance over which illite-chlorite contacts can 644 be discriminated. Beyond this distance, the intracrystalline variation of $\mathrm{Fe}^{3+} / \Sigma \mathrm{Fe}$ ratio in the 645 illite-like phase can be interpreted as an authentic zonation, from 55\% to $85 \%$ in several 646 crystal core clusters

647

648

649 